\title{
Discussion on Land Use Transformation and Land Resource Management Information System Based on Network GIS
}

\author{
Jing Jia ${ }^{1}$ \\ ${ }^{1}$ Wuhan Business University , Wuhan, China, 430056
}

\begin{abstract}
Nowadays, the social economy is developing rapidly, the pace of urbanization is further accelerating, and more and more engineering projects are planned, resulting in greater social demand for land than before, and more and more work in land resource utilization and management. Seriously, people put forward higher requirements for land resource management system. How to use land resources more efficiently and manage land resource information more scientifically has become a key task of relevant land resource management departments. Based on this situation, this article studies the land use transformation and land resource management information system based on network GIS. This article first gives a quick introduction to the management status of land resources, and studies the GIS technology, and then analyzes the needs of the system, the overall framework and development methods of the system, and uses GIS and other related technologies to design and implement a land use Transformation and land resource management information system. At the end of this paper, the designed system has been tested for query speed and query accuracy. The test results show that the query speed of the system is generally faster, with an accuracy rate of $100 \%$.
\end{abstract}

\section{Introduction}

Land resources are one of the most important natural resources and the material basis for human survival and social development. Its non-renewable characteristics further determine the importance of rational land use. The current national conditions of our country are a large population, a small area of arable land, low land quality, and a serious shortage of land resources [1]. This makes the land issue an important strategic issue for our country's modernization. The rational use and management of land is mainly based on detailed investigations of the land, analysis of the quantity, distribution, quality and use of different types of land, and on this basis, the development of land resources is carried out according to the characteristics of the land and the social and economic development of the land. Utilize, formulate strategic plans and arrangements from the perspective of time and space, and then prepare and implement land use plans [2]. Many land resource management departments are still using the traditional work model, that is, using paper media to record and store land-related data. The traditional management model is not only very cumbersome in the management process, but also very difficult in the registration and query functions. The management model is very unscientific, resulting in very low efficiency when using the traditional management model to work. Therefore, in order to get rid of the insufficient level of land resource information management in our country, the construction of land resource management information system is one of the important tasks of our country's geographic space construction [3].

Chinese scholar $\mathrm{Xu}$ Yong believes that the continuous deepening of urbanization has accelerated the actual demand for land resources, resulting in the continuous increase of agricultural land near cities and the problem of rural land contraction. Therefore, in order to effectively solve this problem and make better use of land, it is necessary to rationally plan land use, do a good job in land resource management and land transfer, and avoid waste of resources and land. In order to make contributions to the current social development, more scientific application of land resources is required [4]. Wei Yunlai believes that our country's large land area and rich land resources play an important role in social and economic development and urbanization. Land use is closely related to people's daily life. The management of the earth's resources determines to a large extent the people's living standards. In the modern social and economic development, the conversion and management of land use have gradually become the main content. Under the influence of various factors such as traditional economic development, our country's land resource problems continue to appear, and land transformation and management can play a key role [5]. Che Xin believes that land is the basic condition of people's lives and an important resource in many areas of society. Scientific and efficient use of land resources is of great help to our country's economic development. The work of land use 
transformation and land resource management is very important. The efficient transformation and scientific management of land resources are the prerequisites for the control and efficient use of land resources [6].

Land resources are not a one-time resource. To efficiently use land resources, it is necessary to understand the status of land resources and their changes over time. Understanding detailed real-time land changes is the basic foundation for governments at all levels to formulate land planning and development policies. The use of existing scientific technology and methodological experience to manage land resources more scientifically and accurately is already an urgent task for various land resource management departments. GIS geographic information system is a spatial information technology specially applied to land resource management mode, which is of great significance to today's land resource information management [7]. In order to better manage and share key land use data, and with the help of database technology, network communication technology, GIS technology and information technology, combined with land use planning business and business workflow management, better management and full utilization data, our country urgently needs to establish a land use database management information system to share and manage land resource information data.

\section{Discussion on Land Use Transformation and Land Resource Management Information System Based on Network GIS}

\subsection{System Requirements Analysis}

The preparation of overall land use planning refers to planning experts based on the existing basic information of the planned area. As time goes by, the land use situation and socio-economic conditions in the planned area will change, and the original contradiction in land use Alleviated, disappeared, and new contradictions have arisen and intensified. Therefore, it is necessary to regularly revise the land use planning, and even need to re-formulate the plan [8]. Planning results management is mainly the management of design results obtained from the preparation or revision of the overall land use plan. Manage the results of special designs and related land use project information formed during project implementation. Generally, it mainly includes two types of data: map results and document results. Land use planning implementation business is the process of concretely displaying and applying design results. Once the land use plan is approved, it can be implemented gradually. Taking into account the characteristics of the preparation and review of land use planning, the system uses GIS technology and database technology to provide convenient and effective planning preparation auxiliary tools to assist in the completion of some planning preparations. The system should provide a user-friendly and user-friendly interface, and use appropriate methods to count and display relevant data in order to display the results intuitively and vividly [9]. The system must have a complete principle management function, and each user can only process relevant data at an appropriate level to ensure the security of all data types in the system.

\subsection{Overall System Framework}

In order to obtain good economic and social benefits, some basic principles must be followed when establishing a land use planning management information system. The system should be able to meet the requirements of daily management, results management and design and implementation, and have a certain degree of flexibility and relevance, and conform to the habits of land managers; the design of the management information system can immediately meet the needs of users. All levels require a friendly system interface and comprehensive Internet help, simple operation, easy management, easy upgrade and application [10]. The system provides different permissions for different users, has data protection functions, and the system itself has error detection and fault tolerance functions. Scientifically store general land use planning information, update spatial and characteristic databases in a timely manner, and conduct dynamic business data management. By creating a software system with input, storage, analysis and output functions, it is possible to query, retrieve, analyze and update land use planning information to support the daily office needs of land management. In order to provide intelligence services to relevant functional departments, managers can easily and accurately understand relevant business information and provide intelligence services for superior decision-making [11]. Generally speaking, the land use planning management information system includes interface display, human-computer interaction, scheduling data organization and access, and business data flow processing.

\subsection{System Development Method}

GIS system development methods include independent development, pure secondary development and integrated component development. Independent development is very difficult in the realization of the method, requires a lot of investment and a long development cycle. It is suitable for the development of commercial GIS software platforms, but not for the development of general application systems. When users use pure secondary development, they use the original GIS software as the development platform to develop GIS programs for different application objects. Pure secondary development can directly import many functions from the original platform. Although it is relatively easy to understand, it has poor portability and cannot be used separately from the original system. Evidence-based integrated development refers to the use of GIS functional components provided by GIS software vendors, the program looks better, reliable, easy to transplant and easy to maintain [12]. Therefore, this comprehensive land use planning management 
information system will use computer technology, combined with daily space planning and management work, will use SQL Server 2000 to manage data, implement VB common development language and integrate system software. In VB, the MapInfo Professional platform completes the GIS function of the graphic processing of the overall land use planning. The structure of the system conforms to the needs of the land management department, and it can complete the related work excellently.

\section{System Implementation}

\subsection{Plug-in GIS Framework Design}

In this article, the design of system functions mainly adopts the idea of component-based development model. Split large and complex software applications or divide applications with the same functions into a series of pre-applied, easy to develop, understandable and customizable unit components. Taking GIS secondary development platform development components as an example, it provides various general controls such as map display controls, cartographic controls, layer controls, and toolbar controls. This makes it possible to realize a simple GIS system by directly dragging and dropping these controls onto the form during the development of the GIS system. Based on this, this article extracts the public functions of each subsystem in the land and resources management information system and encapsulates them in the form of plug-ins, which is equivalent to a higher-level component. Then when each subsystem needs these functional modules, just put the corresponding plug-in in the designated folder to achieve the purpose, thus avoiding unnecessary duplication of development work and improving development efficiency. The design of the communication contract interface in the system of this article is mainly realized through three interfaces, namely the host program interface, the plug-in object interface, and the plug-in framework interface.

\subsection{System Function Realization}

The main interface of the system includes menu bar, layer manager, map display, thumbnail, status bar, map right key, layer right key. The menu bar is mainly used to store the functions of each sub-system. The layer manager is used to manage land-related spatial data. The map display is mainly used to display land-related data, spatial positioning, spatial analysis result data, etc. The function of thumbnails is similar to that of slaves. View the position of the map displayed in the map display in the whole map like aerial top view. The status bar is used to display the current user's operation and display the current spatial position coordinates of the mouse in real time. The right button of the map provides the operation function on the map, and the right button of the layer provides the operation function on the layer. Point-shaped mine query is to query and count point-shaped mines, which plays an important role in the planning and utilization of point-shaped mines. Point-shaped mine query can be based on multiple query conditions such as mine number, mine name, mining license number, and mining scale. Multi-condition query can be time-saving and purposeful. Before exporting the parcel map, please perform floor plan loading configuration according to actual needs. The design template setting is to better reflect the automatic exit of the parcel map. The system uses ArcGIS maps to create certain design parameters, element settings, frames, title bars and other content used in standard designs, and creates blocks common to all templates to form a map. Create templates that meet national standards to further improve the efficiency of design and drawing.

\subsection{Metabase Design}

Metadata is used in geospatial information to describe the content, quality, representation, spatial reports, management methods, and other characteristics of geospatial data sets. Spatial data is a kind of data with more complex structure. It includes the description of spatial characteristics, as well as the description of their characteristics and relationships. Therefore, the establishment of spatial metadata templates is a complex task; and due to various reasons, some data organizations or data users have developed spatial data metadata templates that are difficult to be widely accepted by the earth science community. At present, some peripheral devices or some standards have been configured for spatial data metadata. Metadata is descriptive data used to effectively use and exchange data sets. The description of each data element in the data set and the access method of the data user, the retrieval and update of the database. The data also includes information on how to reflect key data as fully as possible according to different data fields. The formulas used in the meta-database design process are:

$$
\begin{gathered}
S=\sum_{i=1}^{n-1} S_{i}+\left(x_{n}+x_{1}\right)\left(y_{1}-y_{n}\right) / 2 \\
S=1 / 2 \sum_{i=1}^{n-1} x_{i}\left(y_{i+1}-y_{i-1}\right) \mid \begin{array}{l}
y_{0}=y_{n} \\
y_{n+1}=y_{1}
\end{array}
\end{gathered}
$$

\section{System Test}

\subsection{Speed Test During System Query}

Table 1. Speed test results of system query process

\begin{tabular}{|c|c|c|}
\hline Query speed & $\begin{array}{c}\text { Number of } \\
\text { items }\end{array}$ & $\begin{array}{c}\text { Proportion of } \\
\text { projects }\end{array}$ \\
\hline High speed & 32 & $64 \%$ \\
\hline The faster & 10 & $20 \%$ \\
\hline Average speed & 6 & $12 \%$ \\
\hline Very slow & 2 & $4 \%$ \\
\hline
\end{tabular}




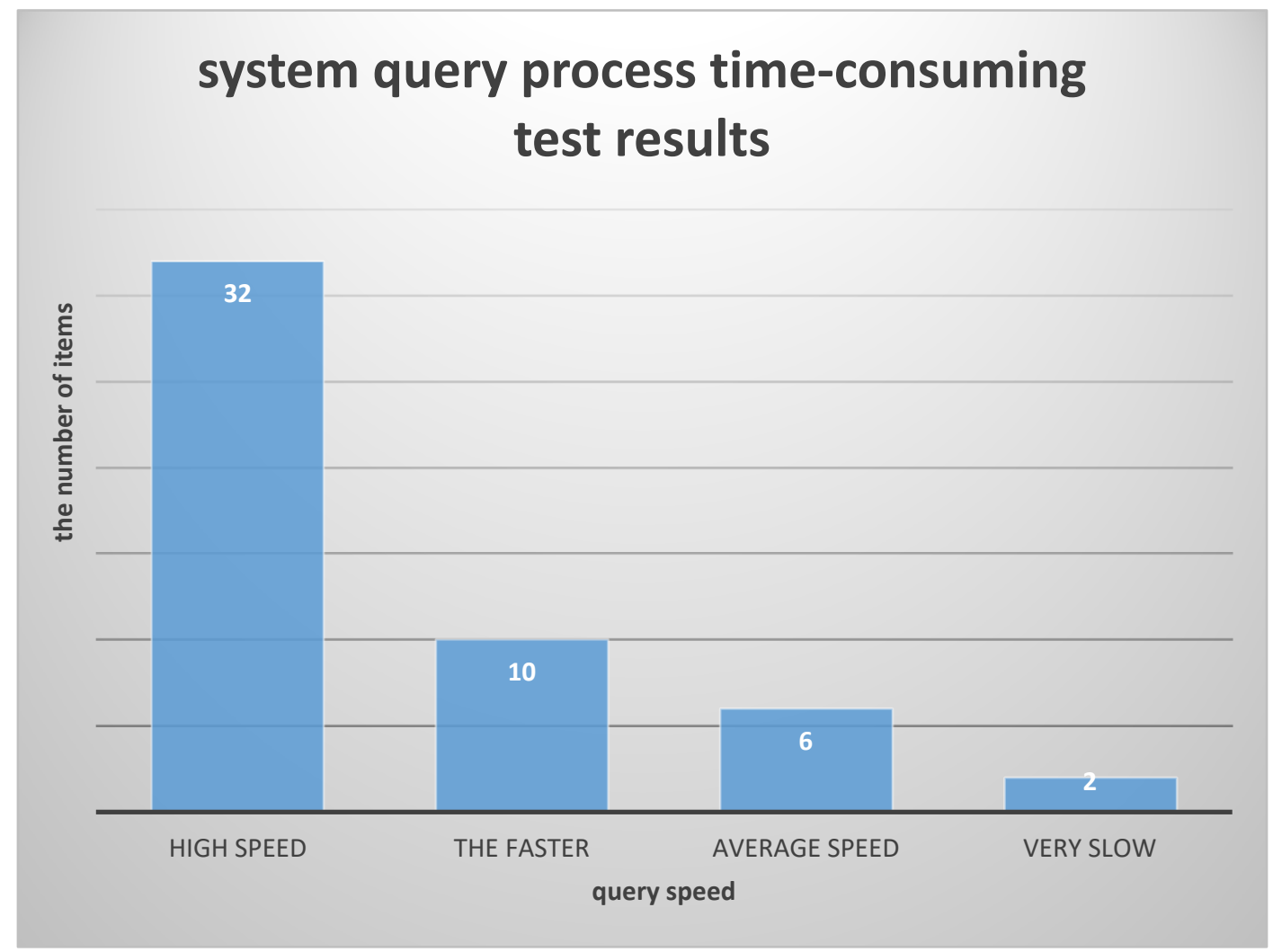

Figure 1. System query process speed test results

According to Table 1 and Figure 1, when testing the speed of the query process of the system, there are a total of 50 items, 32 of which have a very fast query speed, accounting for $64 \%$, and 10 items have a faster query speed. Fast, accounting for $20 \%, 6$ items have an average query speed, accounting for $12 \%$, and 2 items have a very slow query speed, accounting for $4 \%$. Analyzing the data, 42 of the 50 projects have a faster query speed, accounting for $84 \%$. The query speed of 6 projects is generally no problem, and the reason for the slow query speed of the other 2 projects may be Caused by network fluctuations. In general, the land use transformation and land resource management information system based on network GIS designed in this paper is relatively fast in query speed.

\subsection{Export Test During System Query}

Table 2. Test results of the export situation of the system query process

\begin{tabular}{|c|c|c|}
\hline Export situation & Number of items & $\begin{array}{c}\text { Proportion of } \\
\text { projects }\end{array}$ \\
\hline Export correctly & 45 & $90 \%$ \\
\hline Export error & 1 & $2 \%$ \\
\hline Unable to export & 4 & $8 \%$ \\
\hline
\end{tabular}




\section{SYSTEM QUERY PROCESS EXPORT TEST}

\section{RESULTS}

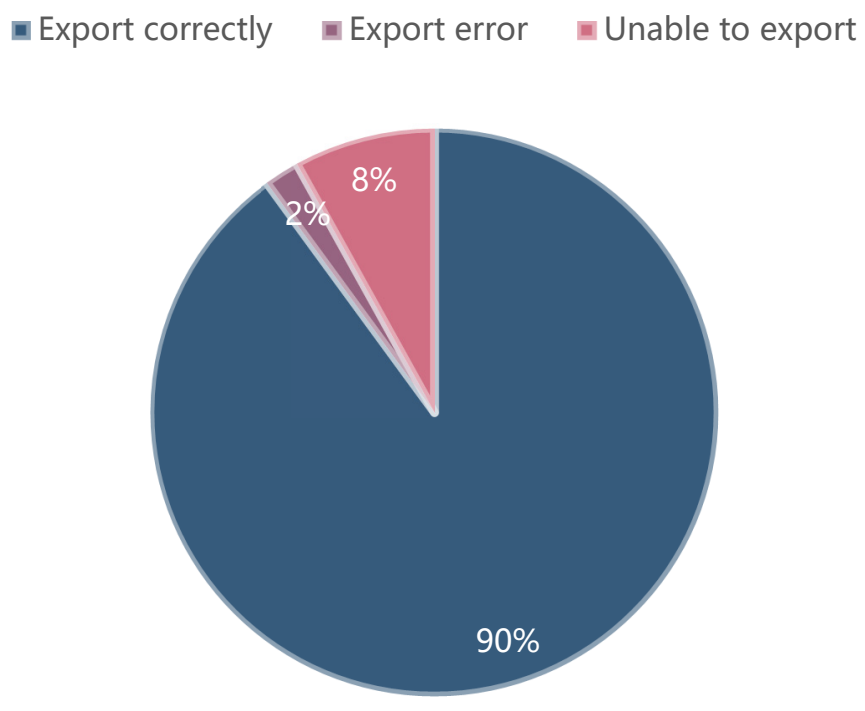

Figure 2. The test results of the export situation of the system query process

According to Table 2 and Figure 2, when testing the export of the query process of the system, there are a total of 50 projects, of which 45 projects are correctly exported, accounting for $90 \%$, and 4 projects cannot be exported, accounting for $8 \%$, and only 1 project was exported incorrectly, accounting for $2 \%$. Analyzing the data, there are 49 items that can be exported correctly and that cannot be exported, accounting for $98 \%$. The reason for the failure to export is caused by network instability. The number of exported wrong items is one, which is caused by a mistake in the input of data by the staff. Excluding items that cannot be exported, the correct rate of export in the query process of the land use transformation and land resource management information system based on network GIS designed in this paper is $100 \%$.

\section{Conclusions}

This article focuses on the application of GIS technology in land use planning and management. Starting from the status quo of land use planning in our country, it discussed in detail the importance of applying GIS technology in land use planning and management, as well as the realization of digitization through various technical means, and scientific management of land use planning and management.This paper examines the development status and achievements of GIS-based land and resources information systems at home and abroad. In response to the daily labor demand of land and related departments, this work proposes a comprehensive framework for land construction and resource management information systems, and uses GIS-related technologies to develop land and resource management. The information system can meet the daily work flow and the needs of various parts of land and resources.

\section{References}

1. Zhang Xiaolin, Jin Xiaobin, Fan Yeting, et al. Analysis on the characteristics and coordination of land use function transformation in Jiangsu Province from 1995 to 2015[J]. Journal of Natural Resources, 2019, 34(04): 689-706.

2. Liu Wen, Zhan Qingming, Zhao Zhongyuan, et al. Analysis and evaluation of the consistency of multi-source land use information for the unified management of natural resources[J]. Journal of Geo-Information Science, 2021, 23(3): 365-376.

3. Wang Huicun. On the main countermeasures of land use transformation and land resource management at county level and below[J]. Modern Agriculture, 2020, No.532(10):74-74.

4. Xu Yong. On land use transformation and land resource management $[\mathrm{J}]$. China Industry Economics, 2020, No.234(02):118-119.

5. Wei Yunlai. Research on Land Resource Management and Land Use Transformation under the New Situation [J]. Geology and Mineral Surveying and Mapping, 2020, 3(2):110-111.

6. Che Xin. Discussion on Land Use Transformation and Land Resource Management[J]. Urban Construction Theory Research (Electronic Edition), 2020, No.326(08):22-22. 
7. Yang Zhiping. Discussion on Land Use Transformation and Land Resource Management Measures[J]. Shanxi Agricultural Economics, 2020, No.280(16): $148+150$.

8. Ma Fenghua. Analysis of Land Use Transition and Land Resource Management[J]. Housing and Real Estate, 2019, No.556(33):138-138.

9. Liu Zhujun. Analysis of Land Use Transition and Land Resource Management Strategy[J]. Science \& Technology Information, 2019, 017(012):230-231.

10. He Ruizhi. Analysis of Land Use Transition and Land Resource Management Strategy[J]. Resource Conservation and Environmental Protection, 2019, 208(03):130.

11. Gong Meijia. The Transformation of Land Use and Land Resource Management[J]. Chinese Place Names, 2019, No.314(09):30-30.

12. Zhang Xiuyun. Discussion on Land Use Transformation and Land Resource Management Methods[J]. Nongjia Staff, 2019, No.625(14):44-44. 